EMBRYARIDDLE
Aeronautical University

SCHOLARLY COMMONS
International Journal of Aviation, Aeronautics, and Aerospace

\title{
Leveraging Aircraft Transponder Signals for Measuring Aircraft Fleet Mix at Non-Towered Airports
}

\author{
Chuyang Yang \\ Purdue University, yang1481@purdue.edu \\ John Mott \\ jhmott@purdue.edu \\ Darcy M. Bullock \\ Purdue,darcy@purdue.edu
}

Follow this and additional works at: https://commons.erau.edu/ijaaa

Part of the Management and Operations Commons, and the Navigation, Guidance, Control and Dynamics Commons

\section{Scholarly Commons Citation}

Yang, C., Mott, J., \& Bullock, D. M. (2021). Leveraging Aircraft Transponder Signals for Measuring Aircraft Fleet Mix at Non-Towered Airports. International Journal of Aviation, Aeronautics, and Aerospace, 8(2). https://doi.org/10.15394/ijaaa.2021.1563

This Article is brought to you for free and open access by the Journals at Scholarly Commons. It has been accepted for inclusion in International Journal of Aviation, Aeronautics, and Aerospace by an authorized administrator of Scholarly Commons. For more information, please contact commons@erau.edu. 


\section{Leveraging Aircraft Transponder Signals for Measuring Aircraft Fleet Mix at Non- Towered Airports}

\section{Cover Page Footnote}

This research was partially funded by the FAA's Partnership to Enhance General Aviation Safety, Accessibility, and Sustainability (PEGASAS) Center of Excellence. The pre-production prototype used in the case study was provided by Bluemac Transportation Data Systems, LLC. The authors have no financial interest in Bluemac Transportation Data Systems. 
The general aviation (GA) sector has contributed significantly to the overall growth of the aviation industry (General Aviation Manufacturers Association, 2018). Fleet mix and operations information is important for the analysis of both the safety and the environmental and economic impact of general aviation activity (Filippone, 2014; Yang et al., 2019). Factual data on the impact of GA activity is particularly important, given the scarcity of airport improvement funds and the strong stakeholder engagement that often occurs when airport investments are evaluated (Mott, 2018).

The research presented herein evaluates Mode $S$ short and extended squitter data collected from three general aviation airports over a one-month period. This article demonstrates that by utilizing the unique International Civil Aviation Administration (ICAO) code present in Mode $\mathrm{S}$ records in the United States, ICAO identification can be used as a primary key for retrieving information from publicly available databases, permitting the determination of aircraft type and engine models. An aircraft operation type with the corresponding fleet mix information can thus be estimated at non-towered airports.

The techniques reported here are also useful in monitoring the increase in aircraft compliant with the Federal Aviation Administration (FAA)'s January 1, 2020 mandate for ADS-B Out to operate in large portions of the national airspace system (FAA, 2021).

\section{Problem Statement}

In the United States, the general aviation industry includes approximately 211,000 aircraft operating in the national airspace system with over 24.8 million annual flight hours. It is estimated that this activity contributes $\$ 219$ billion to the U.S. economy and supports over 1.1 million jobs (General Aviation Manufacturers Association, 2018). However, while local communities benefit from modern air transportation, general aviation also results in a considerable impact from the perspectives of environment and safety. Emissions of pollutants by reciprocating and turbine engines and nuisances from aircraft noise are the two main environmental concerns related to the aviation sector in the area surrounding an airport (Martini et al., 2013). These negative impacts on communities located near airports affect the operations and expansion of those airports and the planning of land use (International Civil Aviation Organization, 2011).

Despite the improving safety record of aviation operations, GA aircraft have traditionally had higher accident and incident rates. In 2018, there were 1,275 GA accidents associated with 381 fatalities in the US, which comprised approximately $97 \%$ of the total number of U.S. civil aviation accidents (Bureau of Transportation Statistics, 2020a, 2020b).

Fleet mix and operations information is important for the analysis of both the safety and the environmental and economic impact of general aviation activity (Filippone, 2014; Yang et al., 2019). Factual data on the impact of GA activity is 
particularly important, given the scarcity of airport improvement funds and the strong stakeholder engagement that often occurs when airport investments are evaluated (Mott, 2018). Hence, to facilitate analysis of both the safety and the environmental and economic impact of general aviation activity, there is a need for developing cost-effective approach to estimate fleet mix and operations information.

\section{Literature Review}

Since the 1970s, the number of people exposed to significant aviation noise has declined from seven million to around four million, while the number of enplanements has increased from 200 million to 850 million during the same time period (FAA, 2018a). The FAA issues Airport Improvement Program (AIP) grants to airport operators and local government to fund projects to sound-insulate homes, schools, and healthcare facilities (FAA, 2018b). The Committee on Aviation Environment Protection (CAEP) was established in 1983 as a technical committee of the ICAO to assist the council in formulating policies and adopting Standards and Recommended Practices (SARPS) related to aircraft noise and emissions, and more generally, to aviation environmental impact (ICAO, 2019). Following the aforementioned ICAO actions, current initiatives such as the Next Generation Air Transportation System (NextGen) in the United States are supported by technology and design programs that address the effects of increased emissions and noise, including the Continuous Lower Energy, Emission and Noise (CLEEN I \& II) program, the Environmentally Responsible Aircraft (ERA) program, and the Subsonic Fixed Wing (SFW) program (Haller, 2012; Nickol, 2011).

The FAA's Aviation Environmental Design Tool (AEDT) is a new software tool which models aircraft performance in space and time to estimate fuel consumption, emissions, noise, and air quality consequences (FAA, 2020). The Aircraft Noise Prediction Program 2 (ANOPP2), which was developed and tested by the U.S. National Aeronautics and Space Administration (NASA), predicts aircraft system and component noise based on flight path and fleet mix information (Lopes \& Burley, 2016). Because the development costs of such programs are substantial, strategic decisions regarding which technologies to pursue in the long term are critical. Bernardo (2012) created a set of generic airports in support of a framework for environmental aviation analysis using fleet-mix information such as the total number of operations and types of aircraft. These generic airports can be used to infer noise-specific trends about specific airports simply by analyzing the generic version, reducing computational demands in early fleet-level airport analysis. To facilitate the estimation of GA exhaust emissions, Huang et al. (2017) developed a statistical model for predicting the fuel flow rate of piston-engine aircraft using general aviation flight operational data such as the aircraft altitude, ground speed, and vertical speed. Martini et al. (2013) performed an analysis of efficiency of 33 Italian non-hub airports considering noise and local air pollution. 
The emission factors for the aircraft specific engines and the number of engines installed on each aircraft type was used to compute the Landing Take-Off (LTO) cycle. A summary of existing airport operations estimation technology is presented in Table 1.

\section{Table 1}

A Summary of Existing Airport Operations Estimation Technology (Muia \& Johnson, 2015)

\begin{tabular}{llll}
\hline Counting Technology & Test & Reported & Cost Per \\
& Airport & Percentage & Unit \\
& Error & &
\end{tabular}

\begin{tabular}{|c|c|c|c|}
\hline \multirow{2}{*}{$\begin{array}{l}\text { Sound-Level Meter Acoustic Counter } \\
\text { (portable acoustic counter) }\end{array}$} & KLAF & $5 \%$ to $99 \%$ & \multirow[t]{2}{*}{$\$ 4,800$} \\
\hline & KTYQ & $8 \%$ to $48 \%$ & \\
\hline \multirow{2}{*}{$\begin{array}{l}\text { Security/Trail Camera (portable camera } \\
\text { with infrared night vision) }\end{array}$} & KLAF & $54 \%$ to $100 \%$ & \multirow[t]{2}{*}{$\$ 1,000$} \\
\hline & KTYQ & $0 \%$ to $43 \%$ & \\
\hline $\begin{array}{l}\text { Stationary Visual Image Detection } \\
\text { (VID) with ADS-B Transponder } \\
\text { Receiver }\end{array}$ & KTYQ & $10 \%$ to $17 \%$ & $\$ 36,000$ \\
\hline \multirow{2}{*}{$\begin{array}{l}\text { Software-defined Radio with ADS-B } \\
\text { Transponder Receiver }\end{array}$} & KLAF & $2 \%$ to $4 \%$ & \multirow[t]{2}{*}{$\$ 7,000$} \\
\hline & KHUF & $5 \%$ & \\
\hline
\end{tabular}

Mott (2018) developed a technology that estimates aircraft operations at non-towered airports based on a combination of ADS-B data and aircraft transponder signal strength. Yang et al. (2019) validated that the accuracy of this technology is greater than that of existing counting technologies, with long-term percentage errors of less than 5\% when compared with official operations counts recorded in the FAA Air Traffic Activity Data System (ATADS) database. This cost-effective technology can be deployed on a large scale to produce accurate operations counts at non-towered airports (McNamara et al., 2016; Mott \& Bullock, 2018; Yang et al., 2019; Mott et al., 2020). In this paper, a novel noise assessment methodology using the previously described aircraft operations counting technology is proposed and validated. 


\section{Methodology}

The authors employed an applied, exploratory research approach for this study. The proposed fleet mix estimation method for non-towered GA airports includes two stages: operations estimation and data integration. Currently, transponder signals transmitted by GA aircraft in the United States include Mode A/C, Mode S Short Squitter (SS), Mode S Extended Squitter (ES), etc. (Table 2).

For Mode $\mathrm{C}$ data, which contains no longitude and latitude information, the corresponding operations count registration heuristics are not germane to this research, as this data does not include a unique ICAO code which provides the ability to retrieve detailed aircraft information (Mott, 2018). With a combination of aircraft squat switch status and altitude trajectory, it is possible to determine with reasonable certainty that an aircraft is landing or taking off at an airport using Mode S SS messages. Mode S data includes by design a unique 24-bit ICAO identifier code (hex code) that is assigned to the aircraft. In the United States, the correspondence between the ICAO hex code and a particular aircraft is both oneto-one and permanent, providing the ability to identify that aircraft once the hex code is known. In addition to traditional Mode S SS signals, information on latitude, longitude, and heading is provided in Mode S ES messages (Mott \& Bullock, 2018).

\section{Table 2}

Data Fields from Transponder Signals (Mott, 2018; Mott \& Bullock, 2018)

\begin{tabular}{llll}
\hline Data Set Field & Mode C & Mode S SS & Mode S ES \\
\hline Timestamp & $\mathrm{X}$ & $\mathrm{X}$ & $\mathrm{X}$ \\
ICAO Hex ID & $\mathrm{N} / \mathrm{A}$ & $\mathrm{X}$ & $\mathrm{X}$ \\
Altitude & $\mathrm{X}$ & $\mathrm{X}$ & $\mathrm{X}$ \\
Heading & N/A & $\mathrm{N} / \mathrm{A}$ & $\mathrm{X}$ \\
Air/Ground & $\mathrm{N} / \mathrm{A}$ & $\mathrm{N} / \mathrm{A}$ & $\mathrm{X}$ \\
Latitude & $\mathrm{N} / \mathrm{A}$ & $\mathrm{N} / \mathrm{A}$ & $\mathrm{DF} 17$ \\
Longitude & $\mathrm{N} / \mathrm{A}$ & $\mathrm{N} / \mathrm{A}$ & $\mathrm{DF} 17$ \\
Signal Strength (8 values) & $\mathrm{X}$ & $\mathrm{X}$ & $\mathrm{X}$ \\
\hline
\end{tabular}

The method for determining detailed aircraft information from Mode $\mathrm{S}$ data includes two stages: operations estimation and fleet mix extraction (Figures 1 and 2). The operations estimation process was developed by Mott and Bullock (2018). 


\section{Figure 1}

General Operation Estimation and Data Integration Process Flow Diagram

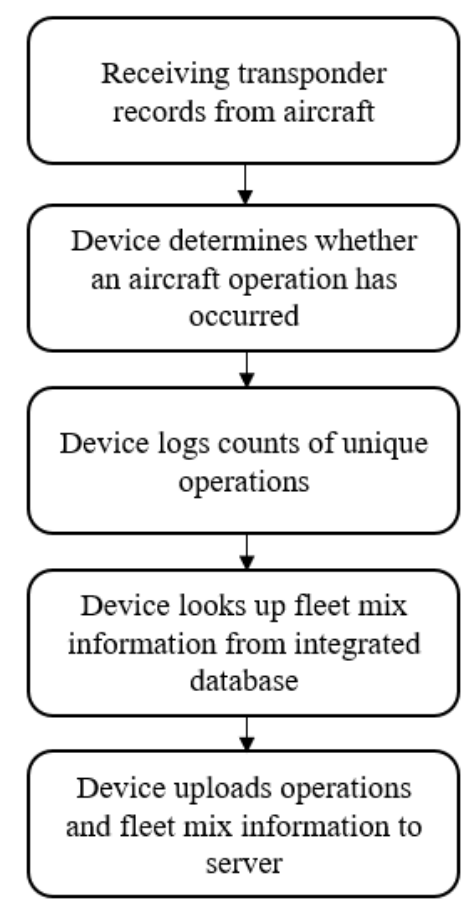

\section{Figure 2}

\section{Schematic of Two Stage Fleet Mix Leverage Process}

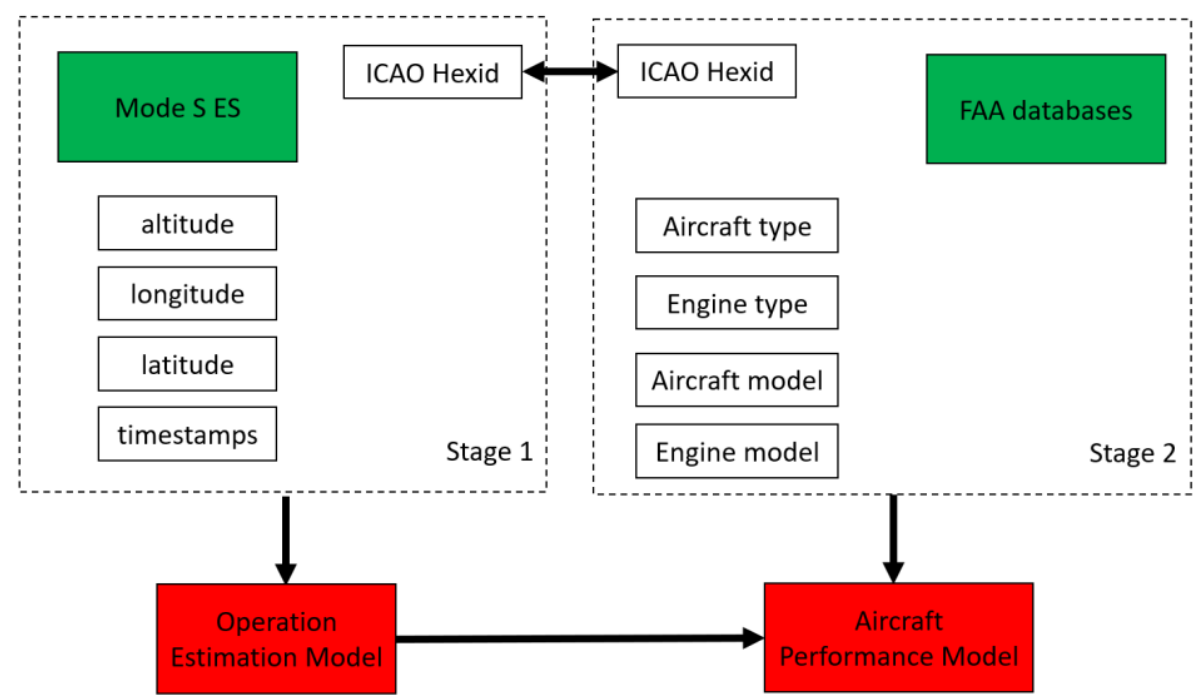


After the count registration process, a data file in .csv format containing daily counts from a typical airport is obtained from the server (Table 3). An aircraft registration master file contains the records of all U.S. Civil Aircraft maintained by the FAA, Civil Aviation Registry, Aircraft Registration Branch, AFS-750 (FAA, 2018c). Two additional reference files, an aircraft reference file and engine reference file, are required to identify the aircraft manufacturer/model/series codes and the engine manufacturer/model codes (Table 4).

\section{Table 3}

Selected Output Information from Aircraft Operations Counting Technologies

\begin{tabular}{ll}
\hline Element & Description \\
\hline Timestamp & The recorded GMT time \\
ICAO Hex code & Mode S Code in hexadecimal format \\
Identification & Identification number assigned to aircraft \\
Reported Altitude & Altitude reported by aircraft \\
Mode S Extended S & 0-None /1- Operations \\
Elementary Mode S & 0-None /1- Operations \\
Mode C & 0-None /1- Operations \\
\hline
\end{tabular}

A data integration process was developed to extract fleet mix information by integrating three publicly available databases maintained by the FAA and described above. The element Aircraft Mfr. Model Code is used as a common main key to combine the aircraft reference database and the aircraft registration master database. The element Engine Mfr. Model Code is used as a common main key to combine the engine reference database and aircraft registration master database. Hence the fleet mix information corresponding to daily operations can be found in the integrated database by referring to the unique ICAO hex code. 


\section{Table 4}

Partial Variables Referred from the FAA Databases (FAA, 2018c)

\begin{tabular}{lll}
\hline Element & Description & Source \\
\hline Type Aircraft & 1-Glider & Aircraft Registration Master file \\
& 2-Balloon & \\
& $\ldots$ & \\
& O=Other & \\
Type Engine & A-None & Aircraft Registration Master file \\
& 1-Reciprocating & \\
& $\ldots$ & \\
& 11-Rotary & \\
Model Name & Name of the aircraft & Aircraft Reference file \\
& model and series & \\
Engine Model Name & The name of & Engine Reference file \\
& Engine model & \\
\hline
\end{tabular}

Yang et al. (2019) deployed transponder data collection units at three general aviation airports in the State of Indiana: Purdue University Airport (ICAO code: KLAF), Terre Haute Regional Airport (ICAO: KHUF), and Indianapolis Executive Airport (ICAO: KTYQ). Monthly data collected from these airports were examined to validate the data integration method in this paper. A full month of transponder records collected from 2017 December at KLAF was retrieved, with a $4.2 \%$ error in the differences between operations counts and the FAA ATADS database. A full month of transponder records collected from May 2019 at KHUF was retrieved with a $1.2 \%$ error in the difference between operations counts and the ATADS database. 27 days of transponder records collected from KTYQ between May 5th, 2019 and May 31, 2019, were also examined. Note that KTYQ is a nontowered airport (Figures 3 and 4). 


\section{Figure 3}

Airport Diagrams of Data Collection Sites (Yang et al., 2019)

a) Purdue University Airport (KLAF)

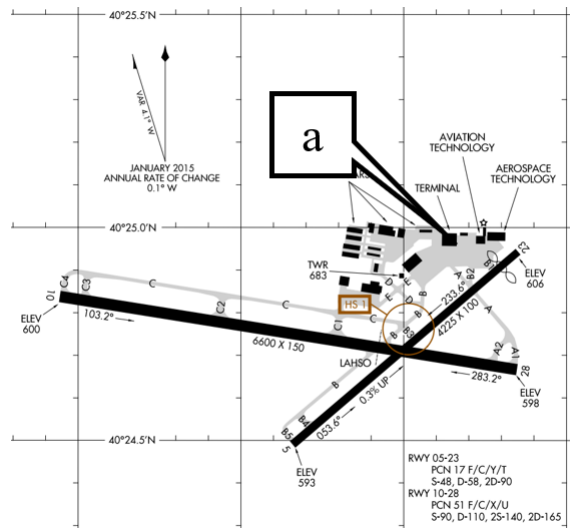

b) Terre Haute Regional Airport (KHUF)

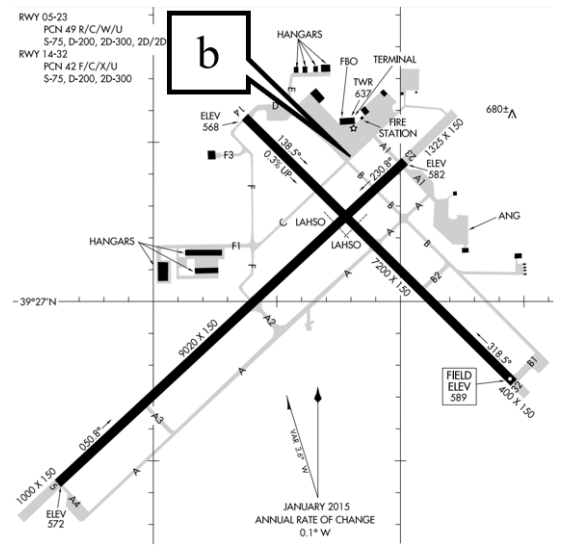

c) Indianapolis Executive Airport (KTYQ)

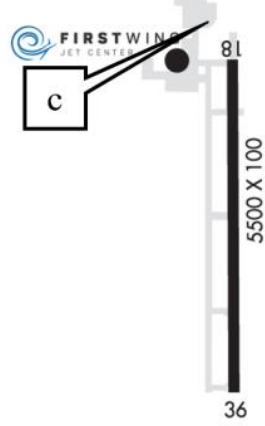




\section{Figure 4}

Field Deployments at Three GA Airports (Yang et al., 2019)

a) Purdue University Airport (KLAF)

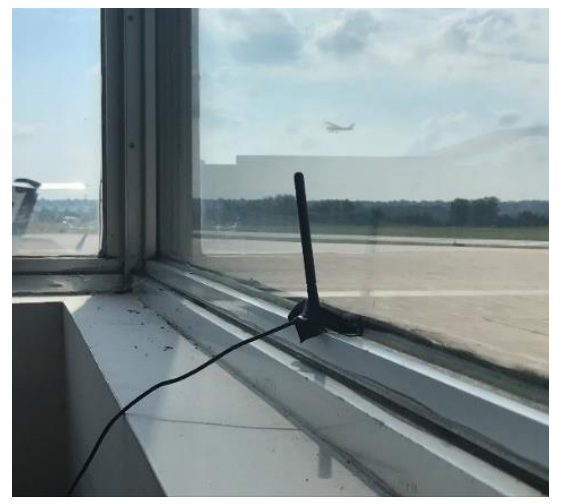

b) Terre Haute Regional Airport (KHUF)

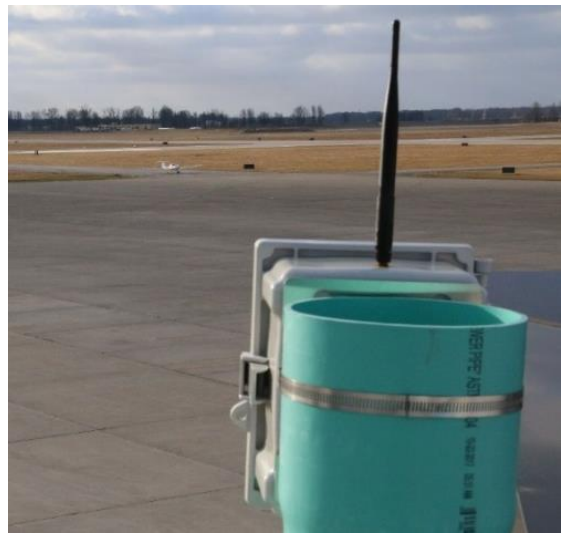

c) Indianapolis Executive Airport (KTYQ)

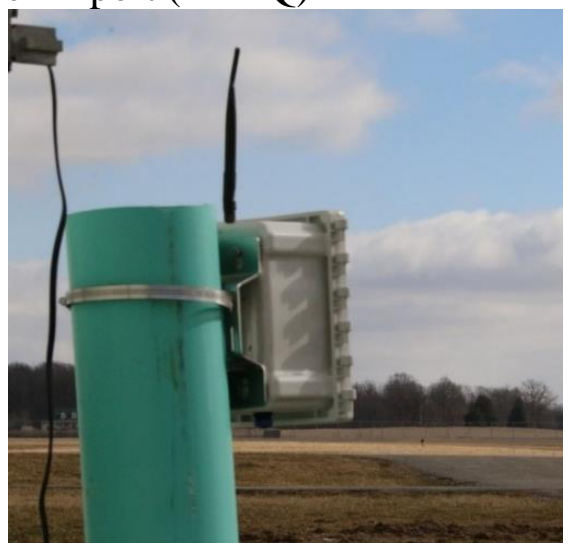




\section{Figure 5}

Fleet Mix Percentages among Aircraft Operated at Three GA Airports

a) Purdue University Airport (KLAF)

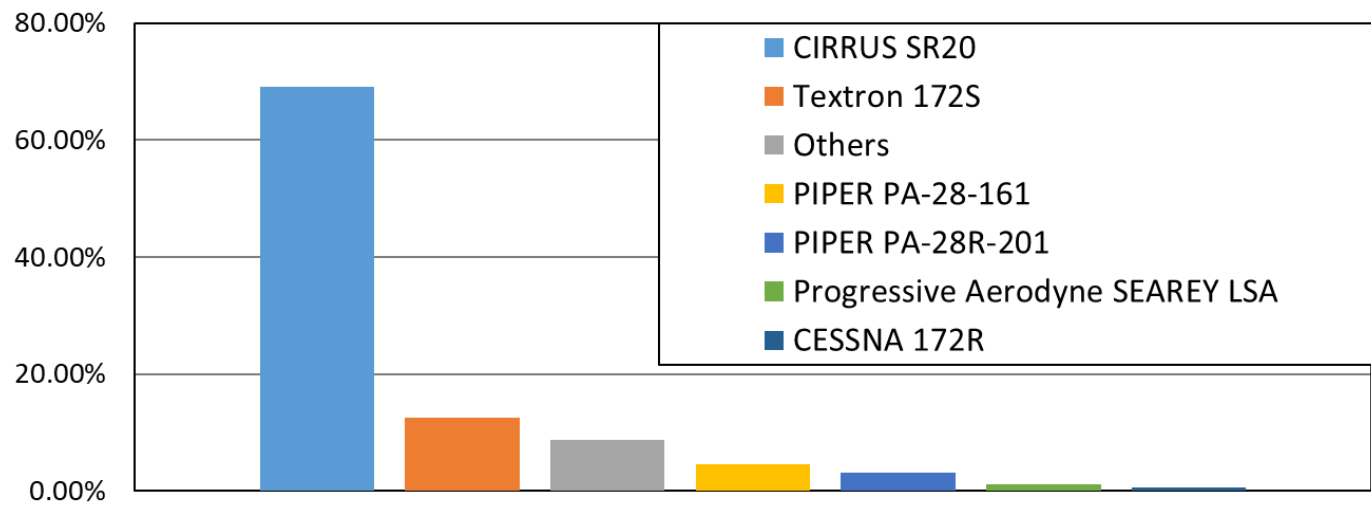

b) Terre Haute Regional Airport (KHUF)

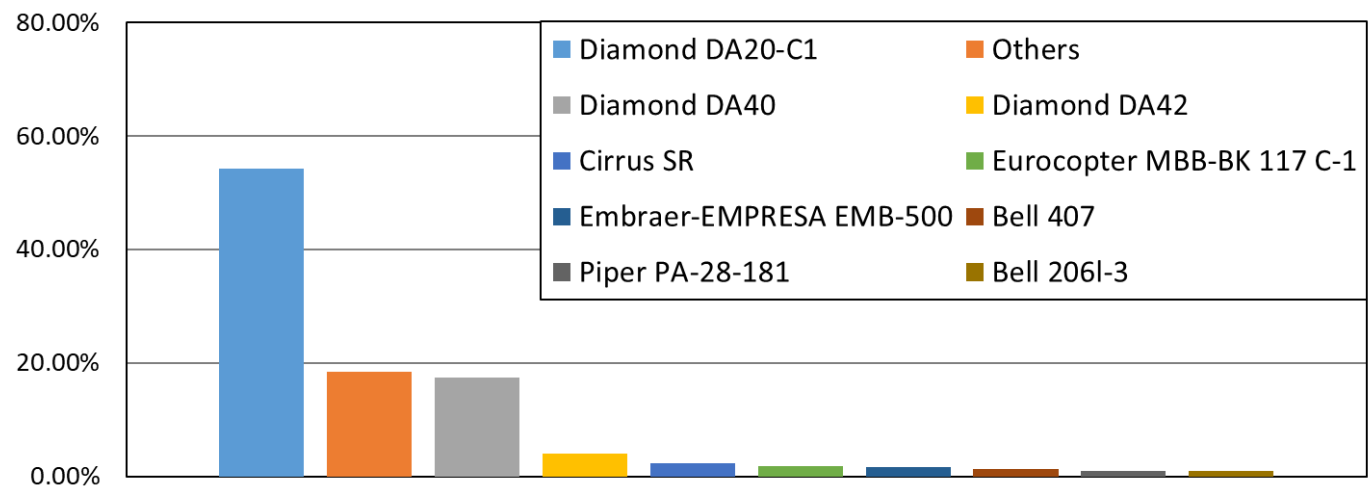

c) Indianapolis Executive Airport (KTYQ)

\begin{tabular}{|c|c|c|}
\hline \multirow{3}{*}{$60.00 \%$} & Others & Cessna $172 S$ \\
\hline & Textron Aviation $172 \mathrm{~S}$ & Cirrus SR 20 \\
\hline & - Cirrus SR 22 & - Piper PA-28-181 \\
\hline \multirow{2}{*}{$40.00 \%$} & Robinson R44 II & Cirrus SR 22T \\
\hline & BEECHCRAFT A36 & - Bell 206B \\
\hline $20.00 \%$ & - Cessna $182 \mathrm{~S}$ & \\
\hline
\end{tabular}




\section{Figure 6}

Engine Model Percentages among Aircraft Operated at Three GA Airports

a) Purdue University Airport (KLAF)

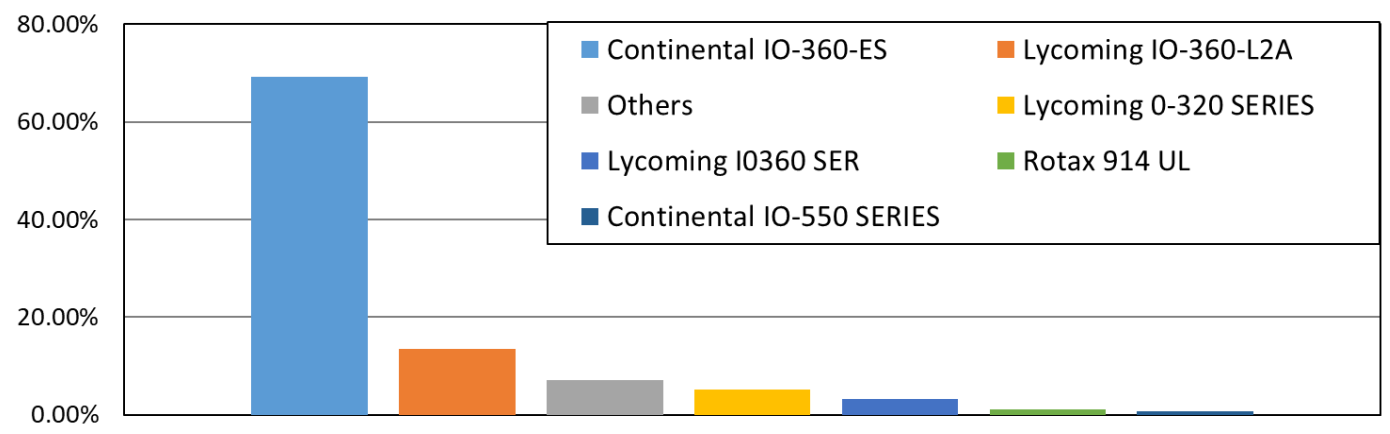

b) Terre Haute Regional Airport (KHUF)

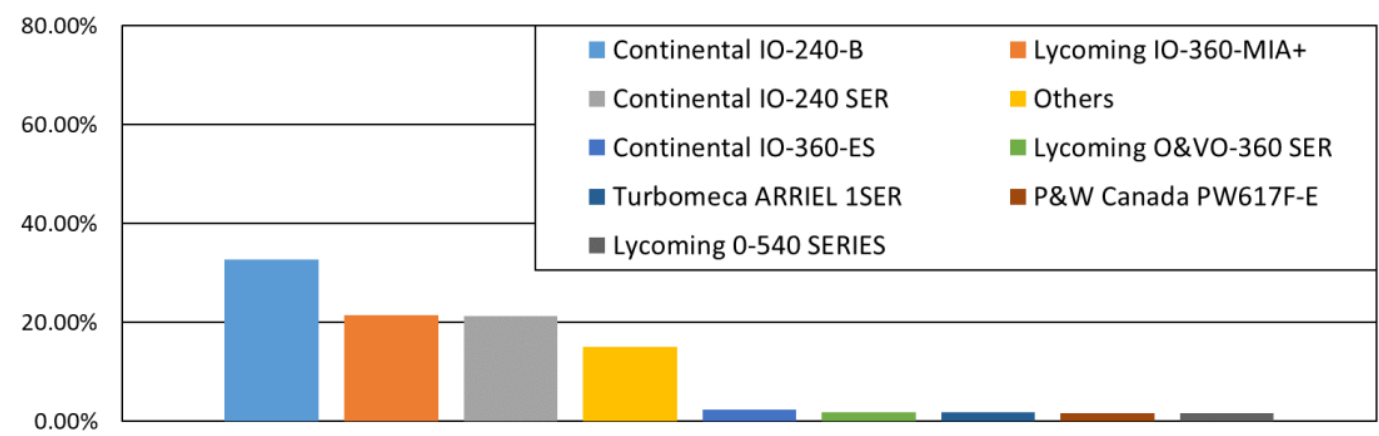

c) Indianapolis Executive Airport (KTYQ)

\begin{tabular}{|c|c|c|}
\hline $80.00 \%$ & Others & Lycoming IO-360-L2A \\
\hline \multirow{3}{*}{$60.00 \%$} & Continental IO-360-ES & Continental IO 520 SERIES \\
\hline & Lycoming O-360-A4M & - Turbomeca ARRIEL 2D \\
\hline & Continental IO-550-N & Lycoming IO-540-AE1A5 \\
\hline \multirow{2}{*}{$40.00 \%$} & Rolls-Royce 250-C47B & Lycoming IO-540 SER \\
\hline & Lycoming IO-540-AB1A5 & Lycoming TIO-540-AJ1A \\
\hline & Lycoming I0360 SER & Lycoming 0-540 SERIES \\
\hline $20.00 \%$ & Continental TSIO-550-K & \\
\hline
\end{tabular}


International Journal of Aviation, Aeronautics, and Aerospace, Vol. 8 [2021], Iss. 2, Art. 1

\section{Figure 7}

An Example of a Training Aircraft, N591PU, at Purdue University Airport $(K L A F)$

a) 3D spatial trajectory
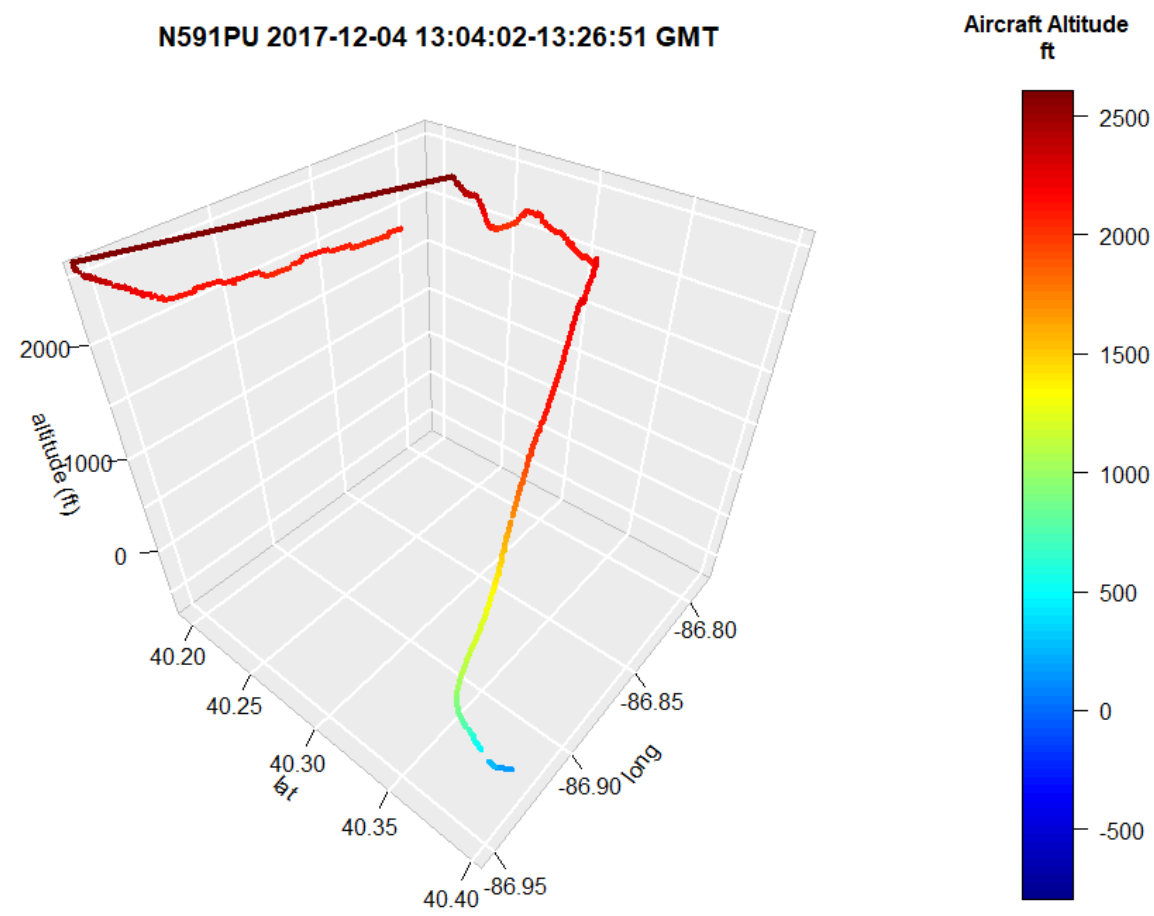

b) $2 \mathrm{D}$ time-series profile

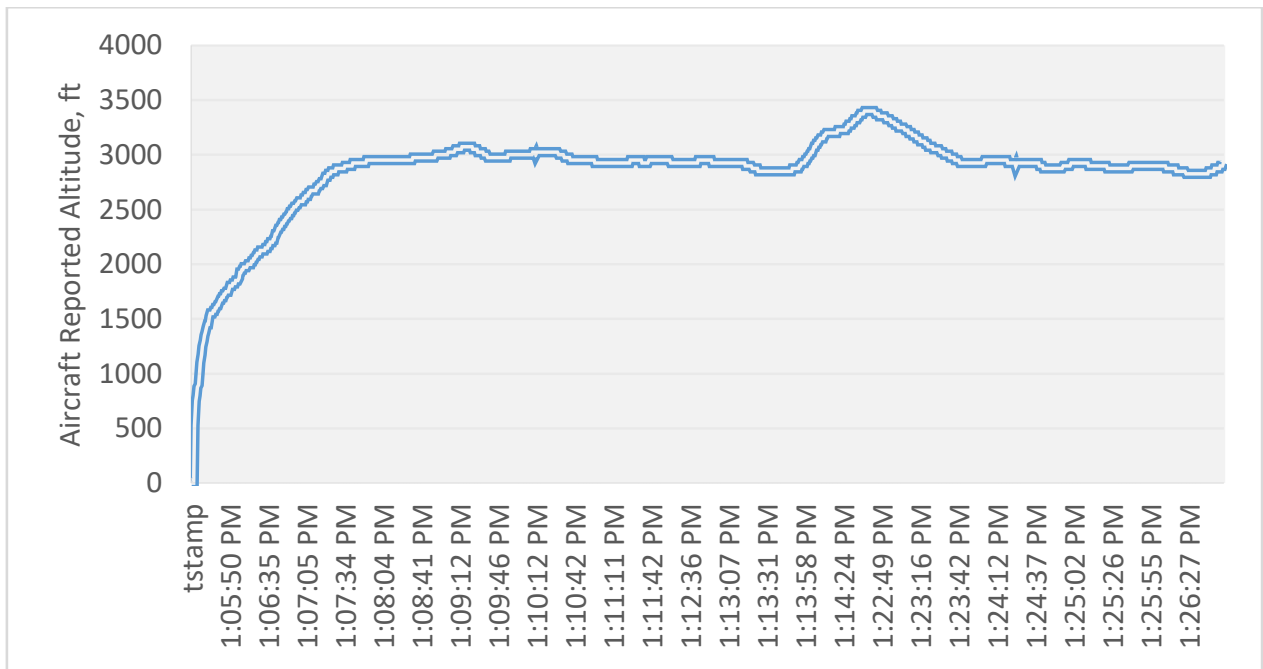


The three graphs in Figure 5 provide an overview of the fleet mix in terms of aircraft type at three general aviation airports over different time periods. Figure 5 a shows the proportion of Mode $\mathrm{S}$ operations at the Purdue University Airport (KLAF) during December 2017. The aircraft with the top five operating frequencies were the Cirrus SR20, Cessna 172S, Piper PA-28R-201, Progressive Aerodyne Sea Ray LSA, and Cessna 172R. Since the professional flight program of the School of Aviation and Transportation Technology at Purdue University (2019) operates a fleet of training aircraft consisting of 14 Cirrus SR20 and 4 Piper PA28R-201, among others, it is reasonable to expect the school's Cirrus fleet to register the greatest number of operations at KLAF. The second graph, Figure 5b, shows the proportion of Mode S operations at Terre Haute Regional Airport (KHUF) in May 2019. The aircraft with the top five operating frequencies at KHUF were the Diamond DA20-C1, Diamond DA40, Diamond DA42, Cirrus SR, and Eurocopter MBB-BK $117 \mathrm{C}-1$. The last graph in Figure 5 shows the proportion of Mode $\mathrm{S}$ operations at Indianapolis Executive Airport (KTYQ) over 27 days in May 2019. The top five aircraft operating at KTYQ during this period corresponded to the Cessna 172S, Textron 172S, Cirrus SR20, Cirrus SR22, and Piper PA-28-181.

The three graphs in Figure 6 summarize of the engine types operated at three general aviation airports over the same time period as represented in Figure 5. Figure 6a shows the proportion of engines operated by the Mode S-equipped fleet at KLAF during December 2017. The five engine models operating most frequently were the Continental IO-360-ES, Lycoming IO-360-L2A, Lycoming O-320 Series, Lycoming IO-360 series, and Rotax 914UL. The second graph, Figure 6b, shows the proportion of engines operated by the Mode S-equipped fleet at KHUF in May 2019. The five engine models operating most frequently at KHUF were the Continental IO-240-B, Lycoming IO-360-M1A, Continental IO-340 Series, Continental IO-360-ES, and Lycoming O\&VO-360 Series. The last graph in Figure 6 depicts the proportion of engines operated by the Mode S-equipped fleet at KTYQ during 27 days in May 2019. The five engine models operating most frequently at KHUF were the Lycoming IO-360-L2A, Continental IO-360-ES, Continental IO520 Series, Lycoming O-360-A4M, and Turbomeca Arriel 2D.

An example of a Cirrus SR 20 (piston-single) training aircraft N591PU under LTO cycle (13:04:02-13:26:51 GMT, December 4th, 2017) at Purdue University Airport (LAF) was obtained in a 3D spatial view and 2D time-series view (Figure 7). In this case, a total of 1,050 Mode S ES signals were collected and analyzed. N591PU started taxiing at 13:04:02 GMT and climbing at 13:04:11 GMT at $525 \mathrm{ft}$ (reported altitude), then finished the takeoff stage at 13:08:53 at $3000 \mathrm{ft}$.

\section{Conclusions}

The general aviation sector has contributed significantly to the overall growth of the aviation industry, resulting in substantial economic benefits to communities; however, emissions of air pollutants and noise from these aircraft are 
two primary environmental concerns. Information related to fleet mix and operations is therefore potentially useful for the modeling of aircraft performance at non-towered GA airports. Short- and extended-squitter Mode S data collected from three general aviation airports over a one-month period were examined and analyzed; the analysis suggests that the unique ICAO identification code present in Mode $S$ records does indeed serve as an appropriate primary key for the retrieval of information from other sources. Using data integration and mining techniques, aircraft and engine model information was extracted from public databases.

\section{Recommendations}

Federal regulations 14 CFR 91.225 and 14 CFR 91.227 promulgated by the FAA dictate that aircraft operating in most types of controlled airspace after January 1, 2020 are required to have an Automatic Dependent SurveillanceBroadcast (ADS-B) system that includes a certified position source capable of meeting regulatory requirements (Office of Register \& Government Publishing Office, 2020a, 2020b). For an indication of the status of the air traffic system with respect to ADS-B equipage, Table 5 displays the percentage of transponder messages broadcast as Mode S SS (altitude and ICAO identifier only) versus Mode S ES at four airports: KLAF, KHUF, KTYQ, and KASW. As the NextGen 2020 deadline for ADS-B Out was passed, the percentage of ADS-B reporting aircraft showed a corresponding increase (Table 6) (FAA, 2021). It is reasonable to assume, based on this data, that Mode $\mathrm{S}$ is a feasible and available data source for the future research of sustainable economic and environmental assessment at GA nontowered airports.

\section{Table 5}

Transponder Message Proportions Based on Operations At Three GA Airports (KLAF, KHUF, and KTYQ)

\begin{tabular}{llll}
\hline & KLAF & KHUF & KTYQ \\
\hline Mode C & $2.8 \%$ & $5.2 \%$ & $3.0 \%$ \\
Mode S SS & $18.1 \%$ & $65.6 \%$ & $57.1 \%$ \\
Mode S ES & $79.1 \%$ & $29.2 \%$ & $39.9 \%$ \\
\hline
\end{tabular}




\section{Table 6}

U.S. GA Fixed-Wing Equipage and Avionics Performance Data (FAA, 2021)

\begin{tabular}{llll}
\hline Date & Equipped & $\begin{array}{l}\text { Overall } \\
\text { Percentage of GA } \\
\text { aircraft }(\%)\end{array}$ & $\begin{array}{l}\text { Performing } \\
\text { Installation }\end{array}$ \\
\hline 1-Jan-20 & 84,317 & 39.9 & 78,264 \\
1-Feb-20 & 86,500 & 40.9 & 80,187 \\
1-Mar-20 & 90,084 & 42.7 & 83,498 \\
1-Apr-20 & 92,646 & 43.9 & 85,556 \\
1-May-20 & 94,738 & 44.9 & 87,125 \\
\hline
\end{tabular}

An opportunity for future work is the extraction of additional information from the integrated database, including the number of engines, the weight of aircraft, engine horsepower, and pounds of thrust. Further improvements to the count registration process will increase the accuracy of operations counts and fleet mix information. Research in both areas may serve to facilitate the development of more accurate aircraft performance models for the analysis of both the safety and the environmental and economic impact of general aviation operations. 


\section{References}

Bernado, J. E. (2012). Development and assessment of generic airport for fleetlevel noise modeling. Partnership for AiR Transportation Noise and Emissions Reduction (PARTNER): 9th Annual Joseph A. Hartman Student Paper Competition. Retrieved from http://web.mit.edu/aeroastro/partner/re ports/hartman/bernardo-13.pdf

Bureau of Transportation Statistics. (2020a). U.S. general aviation safety data. Retrieved from https://www.bts.gov/content/us-general-aviationa-safetydata

Bureau of Transportation Statistics. (2020b). U.S. air carrier safety data. Retrieved from https://www.bts.gov/content/us-air-carrier-safety-data

Federal Aviation Administration. (2018a). FAA history of noise. Retrieved from https://www.faa.gov/regulations_policies/policy_guidance/noise/history/

Federal Aviation Administration. (2018b). 2019-2023 national plan of integrated airport system (NPIAS) report. Washington, D.C: Author. Retrieved from https://www.faa.gov/airports/planning_capacity/npias/current/historical/ media/2019/NPIAS-Report-2019-2023-Narrative.pdf

Federal Aviation Administration. (2018c). Aircraft registry: Releasable aircraft database download. Washington, D.C: Author. Retrieved from https://www.faa.gov/licenses_certificates/aircraft_certification/ aircraft_registry/releasable_aircraft_download/

Federal Aviation Administration. (2020). Aviation environmental design tool (AEDT). Washington, D.C: Author. Retrieved from https://aedt.faa.gov/

Federal Aviation Administration. (2021). Current equipage levels. Washington, D.C: Author. Retrieved from https://www.faa.gov/nextgen/equipadsb /installation/current_equipage_levels/

Filippone, A. (2014). Aircraft noise prediction. Progress in Aerospace, 68,27-63. doi:10.1016/ j.paerosci.2014.02.001

General Aviation Manufacturers Association. (2018). 2018 annual report. Washington, D.C: Author.

Haller, B. (2012). Overview of subsonic fixed wing project: Technical challenges for energy efficient, environmentally compatible subsonic transport aircraft. 3rd NASA Glenn Propulsion Control \& Diagnostics Workshop, Cleveland, OH. Retrieved from https://www.grc.nasa.gov/WW W/cdtb/aboutus/workshop2012/Presentations/Plenary\%20Session\%20Pres entations/2012_02_28\%20Lunch\%20-\%20Haller_SFW.pdf

Huang, C., Xu, Y., \& Johnson, M.E. (2017). Statistical modeling of the fuel flow rate of GA piston engine aircraft using flight operational data. Transportation Research Part E, 50, 50-62. Retrieved from https://doi.o rg/10.1016/j.trd.2017.03.023 
International Civil Aviation Organization. (2011). Aircraft noise: Balanced approach to aircraft noise management. Retrieved from https://www.icao.int/environmental-protection/Pages/noise.aspx

International Civil Aviation Organization. (2019). Committee on aviation environmental protection (CAEP). Retrieved from https://www.icao.int/ environmental-protection/Pages/Caep.aspx

Lopes, L. V., \& Burley, C. L. (2016). ANOPP user's manual: Version 1.2. Hampton, VA: NASA Langley Research Center. Retrieved from https://ntr s.nasa.gov/api/citations/20160014858/downloads/20160014858.pdf

Martini, G., Manello, A., \& Scotti, D. (2013). The influence of fleet mix. Ownership and LCCs on airports' technical/environmental efficiency. Transportation Research Part E, 50, 37-52. doi: 10.1016/j.tre.2012.10.005

McNamara, M. L., Mott, J. H., \& Bullock, D. M. (2016). Leveraging aircraft avionics for fleet and airport management. Transportation Research Record: Journal of the Transportation Research Board, 2569(1), 32-41. Retrieved from https://doi.org/10.3141/2569-04

Mott, J. H. (2018). Estimation of aircraft distances using transponder signal strength information. Cogent Engineering, 5(1). Retrieved from https://do i.org/10.1080/23311916.2018.1466619

Mott, J. H., \& Bullock, D. M. (2018). Estimation of aircraft operations at airports using mode-C signal strength nformation. IEEE Transactions on Intelligent Transportation Systems, 19(3), 677-686. doi:10.1109/TITS.2017.2700764

Mott, J. H., Yang, C., \& Bullock, D. M. (2020). Atmospheric pressure calibration to improve accuracy of transponder-based aircraft operations counting technology. Journal of Aviation Technology and Engineering, 9(2). Retrieved from https://doi.org/10.7771/2159-6670.1222

Muia, M. J., \& Johnson, M. E. (2015). Evaluating methods for counting aircraft operations at non-towered airports. Washington, D.C.: National Academies of Sciences, Engineering, and Medicine. Retrieved from https://doi.org/10.17226/22182.

Nickol, C. (2011). Environmentally responsible aviation (ERA) project: Assessing progress toward simultaneous reductions in noise, fuel burn and NOx. National Aeronautics and Space Administration (NASA). 49th AIAA Aerospace Sciences Meeting, Reston, VA. Retrieved from https://fli ght.nasa.gov/pdf/asm_presentations_simultaneous_reductions_noise_fuel_ nox.pdf

Office of Register \& Government Publishing Office. (2020a). § 91.225 Automatic Dependent Surveillance-Broadcast (ADS-B) Out equipment and use. Electronic Code of Federal Regulations. Retrieved from 
https://www.ecfr.gov/cgi-bin/text-idx?SID=40fd0dfacfb9fca4e2a259dc $\mathrm{d} 058914 \mathrm{a} \& \mathrm{mc}=$ true $\&$ node $=\mathrm{pt} 14.2 .91 \& \mathrm{rgn}=$ div5\#se14.2.91_1225

Office of Register \& Government Publishing Office. (2020b). § 91.227 Automatic Dependent Surveillance-Broadcast (ADS-B) equipment performance requirements. Electronic Code of Federal Regulations. Retrieved from https://www.ecfr.gov/cgi-bin/text-idx?SID=40fd0dfacfb9fca4e2a259dcd0 $58914 \mathrm{a} \& \mathrm{mc}=$ true $\&$ node $=\mathrm{pt} 14.2 .91 \& \mathrm{rgn}=\operatorname{div} 5 \#$ se14.2.91_1225

Pavan, A. P., Gavrilovski, A., Jimenez, H., \& Mavris, D. (2017). Improvement of rotorcraft safety metrics using performance models and data integration. Journal of Aerospace Information Systems, 14(1), 26-40. Retrieved from https://doi.org/10.2514/1.I010467

Puranik, T., Harrison, E., Chakraborty, I., \& Mavris, D. (2020). Aircraft performance model calibration and validation for general aviation safety analysis. Journal of Aircraft, 57(4). Retrieved from https://doi.org /10.2514/1.C035458

Purdue University. (2019). Aviation and transportation technology fleet. West Lafayette, IN: Author. Retrieved from https://polytechnic.purd ue.edu/schools/aviation-and-transportation-technology/about/fleet

Yang, C., Mott, J. H., Hardin, B., Zehr, S., \& Bullock, D. M. (2019). Technology assessment to improve operations counts at non-towered airports. Transportation Research Record: Journal of the Transportation Research Board, 2673(3),44-50. Retrieved from https://doi.org/10.1177/036119811 9835804 